Feijen-de Jong, E.I., Jansen, D.E.M.C., Baarveld, F., Boerleider, A.W., Spelten, E., Schellevis, F/ Reijneveld, S.A. Determinants of prenatal health care utilisation by low-risk women: a

\begin{tabular}{l|l}
$\begin{array}{l}\text { Postprint } \\
\text { Version }\end{array}$ & 1.0 \\
\hline $\begin{array}{l}\text { Journal website } \\
\text { Pubmed link }\end{array}$ & $\underline{\text { http://linkinghub.elsevier.com/retrieve/pii/S1871-5192(15)00007-4 }}$ \\
\hline DOI & 10.1016/j.wombi.2015.01.005
\end{tabular}

This is a NIVEL certified Post Print, more info at http://www.nivel.eu

\title{
Determinants of prenatal health care utilisation by low-risk women: A prospective cohort study
}

\author{
ESTHER I. FEIJEN-DE JONG A, , DANIELLE E.M.C. JANSEN ${ }^{\text {B, C, G, }}$, FRANK BAARVELD ${ }^{\text {D, H, }}$,

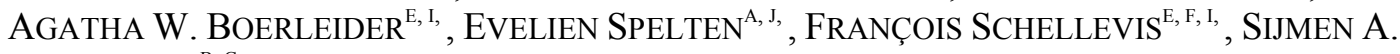 \\ REIJNEVELD ${ }^{\mathrm{B}, \mathrm{G},}$
}

\begin{abstract}
Background: Prenatal health care is pivotal in providing adequate prevention and care to pregnant women.

Aim: We examined the determinants of inadequate prenatal health care utilisation by low-risk women in primary midwifery-led care in the Netherlands. Methods: We used longitudinal data from the population-based DELIVER study with 20 midwifery practices across the Netherlands in 2009 and 2010 as the experimental setting. The participants were 3070 pregnant women starting pregnancy care in primary midwifery care.

Findings: We collected patient-reported data on potential determinants of prenatal care utilisation derived from the Andersen model. Prenatal health care utilisation was measured by a revised version of the Kotelchuck Index, which measures a combination of care entry and number of visits. Low-risk pregnant women (not referred during pregnancy) were more likely to use prenatal care inadequately if they intended to deliver at a hospital, if they did not use folic acid adequately periconceptionally, or if they were exposed to cigarette smoke during pregnancy. Among those who were referred to secondary care, women reporting a chronic illnesses or disabilities, and women who did not use folic acid periconceptionally were more likely to make inadequate use of prenatal care.

Conclusion: Inadequate prenatal health care use in primary midwifery care is more likely in specific groups, and the risk groups differ when women are referred to secondary care. The findings suggest routes that can target interventions to women who are at risk of not adequately using prenatal prevention and care services.
\end{abstract}


Feijen-de Jong, E.I., Jansen, D.E.M.C., Baarveld, F., Boerleider, A.W., Spelten, E., Schellevis, F Reijneveld, S.A. Determinants of prenatal health care utilisation by low-risk women: a prospective cohort study. Women and Birth: 2015, 28(2), 87-94

\section{INTRODUCTION}

Adequate use of prenatal health care is essential for mother and baby in reducing morbidity and mortality rates. ${ }^{1,2}$ and 3 A timely start (during the first trimester) and an adequate number (according to professional guidelines) of prenatal care visits are important determinants of maternal and foetal health., ${ }^{2,4}$ and 5 Availability of prenatal care may strongly influence adequate use. However, even in the case of optimal availability, some women do not make adequate use of prenatal care. ${ }^{6}$

Several determinants of inadequate prenatal health care utilisation have been identified. Smoking, low maternal age, low educational level, non-marital status, ethnic minority status, planned pattern of prenatal care, hospital type, planned place of delivery, uninsured status, high parity, prior premature birth, obstetric risk factors, late recognition of pregnancy, and living in deprived neighbourhoods are all associated with inadequate health care utilisation. ${ }^{6}$ However, most studies identifying determinants of prenatal health care utilisation include heterogeneous populations of both low- and high-risk pregnant women. ${ }^{6}$ Specific evidence on determinants of prenatal health care utilisation by low-risk women (women who are not known to have any medical or obstetric risk factors before the onset of labour, ${ }^{7}$ ) is lacking. This is remarkable as the majority of pregnancies (80-90\%) are considered to be low-risk. 8 and 9

The organisation of maternity care in the Netherlands enables the study of low-risk pregnant women and also the assessment of determinants of inadequate health care utilisation in women who may be at low-risk at the beginning of pregnancy, but become high risk later. Dutch maternity care is organised into primary, secondary and tertiary care. Low-risk women mainly attend midwives and, to a small degree, general practitioners $(2-6 \%) .{ }^{10}$ Women are defined as low-risk and are referred to secondary care according to an Obstetrics and Midwifery Manual. This Manual aligns provider competencies with the health status of pregnant women. It is developed and revised over decades with input of midwives and gynaecologists. ${ }^{11}$ High-risk women attend obstetricians and specialised midwives in general hospitals (secondary care), while tertiary care occurs in university hospitals. There is close mutual cooperation between these different strata. ${ }^{10}$

The aim of this research is to examine determinants of inadequate prenatal health care use by low-risk women in primary midwifery-led care in the Netherlands, and to determine whether these differ from those who are referred to prenatal secondary care. Information and knowledge about these determinants can optimise professional guidelines in prenatal care and can support the development of tailored interventions for the groups that make inadequate use of prenatal care.

We used Andersen's behavioural model of health care utilisation as a guiding framework to categorise the determinants of health care utilisation. ${ }^{12}$ This model suggests that the utilisation of health care services depends on predisposing, enabling, need and health behaviour factors. ${ }^{12}$ 
Feijen-de Jong, E.I., Jansen, D.E.M.C., Baarveld, F., Boerleider, A.W., Spelten, E., Schellevis, F Reijneveld, S.A. Determinants of prenatal health care utilisation by low-risk women: a prospective cohort study. Women and Birth: 2015, 28(2), 87-94

\section{SUBJECTS AND METHODS}

Data for this analysis were obtained from the DELIVER study (Dutch acronym for 'data primary care delivery') conducted by the Department of Midwifery Science of VU University Medical Center, Amsterdam. ${ }^{13}$ DELIVER was a descriptive study that aimed to provide information about the organisation of midwifery care, the accessibility of midwifery care, and the quality of primary midwifery care in the Netherlands.

DELIVER used a two-stage sampling procedure. Firstly, midwifery practices were recruited by using purposive sampling. Subsequently, all clients receiving care in the participating primary midwifery practices at any time in a 12-month study period in 2009-2010 were eligible to participate if they were able to understand Dutch, English, Turkish or Arabic. The participating practices (20 of the 519 midwifery practices in the Netherlands) comprised 110 midwives and a caseload of 8200 clients per year, representing all regions of the Netherlands. The women included in our study: (a) started their prenatal care in a primary care midwifery practice at the beginning of their pregnancy, (b) filled in the first questionnaire in the DELIVER study, and (c) the data from their questionnaire could be linked to the electronic client data and the Netherlands Perinatal Registry data (Fig. 1).

\section{[FIGURE 1]}

Clients participating in the DELIVER study completed up to three questionnaires, depending on the date of their first appointment in midwifery practice during the study period. The first questionnaire was administered before 34 weeks of gestation, the second between 34 weeks of gestation and birth, and the third six weeks postpartum. In addition, data was collected about the care provided by midwives by extracting data from electronic client records of participating clients and from the Netherlands Perinatal Registry, including obligatory reporting of a standardised set of data. Unique anonymous client identifiers and anonymous midwifery practice identifiers linked the three data sources. ${ }^{13}$

The Medical Ethics Committee of VU University Medical Center, Amsterdam approved the study protocol of the DELIVER study, including written informed consent.

This study used data from the first questionnaire (before 34 weeks of gestation), the electronic client records and data from the Netherlands Perinatal Registry.

Prenatal health care utilisation was measured by using the Kotelchuck Index, which is widely used in the US. ${ }^{14}$ We constructed a revised index, modified according to the guidelines of the Royal Dutch Organization of Midwives, concerning the number of prenatal visits during pregnancy. In the Netherlands a relatively high number of prenatal visits is advised, starting care before the 10th week of pregnancy leading to an average of 14 visits at 40 weeks of gestation, compared to, e.g. the NICE guideline ${ }^{15}$ in which 10 appointments for nulliparous women and 7 for parous women is advised for women who are healthy and whose pregnancies remain 
Feijen-de Jong, E.I., Jansen, D.E.M.C., Baarveld, F., Boerleider, A.W., Spelten, E., Schellevis, F Reijneveld, S.A. Determinants of prenatal health care utilisation by low-risk women: a prospective cohort study. Women and Birth: 2015, 28(2), 87-94

uncomplicated in the prenatal period. The adjusted Kotelchuck Index combines the timing of initial prenatal health care and the number of prenatal health care visits. Prenatal visits were defined as face-to-face contact with a midwife in primary care. Late initiation of care was defined as a first visit after 12 weeks of gestation (defined by the midwife on the basis of ultrasound examination or the first day of the last menstrual period). The number of visits was calculated on the basis of the electronic client records, which were kept by midwives. More than one visit a day at the same place was counted as one visit. The gestational age at referral was determined for women who were referred to secondary care. Four categories of prenatal health care utilisation were defined: Inadequate Care, Intermediate Care, Adequate Care and Adequate Plus ( Table 1). These categories were dichotomised into Adequate (adequate) and Inadequate (inadequate and intermediate) Care. The Adequate Plus group was excluded because it was not relevant in view of the aim of this study.

\section{[TABLE 1]}

Referrals to secondary care were identified using data from the Netherlands Perinatal Registry. Women with no referrals during pregnancy were classified as non-referred, while women with a referral during pregnancy were classified as referred. Referrals during labour were classified as non-referred. We assumed that these referrals were not associated with prenatal health care utilisation.

Possible determinants of health care utilisation concerned predisposing, enabling, need and health behaviour variables. Data on determinants were obtained from the questionnaire. Several variables, based on Andersen's model, were considered to be potential determinants of health care utilisation. Operationalisations of the independent variables are shown in Fig. 2. Predisposing variables encompassed socio-demographic and belief factors. Enabling variables included finance (health care insurance) and organisation (accessibility of care) variables. Regarding health insurance, we distinguished basic and supplementary health care insurance. In the Netherlands every inhabitant has obligatory basic health insurance, however, reimbursement of the costs for midwifery-led hospital births requires supplementary insurance. Need variables comprised the health status (perceived and evaluated) of the client. The descriptive component of EuroQol was used to measure self-reported health status. ${ }^{16}$ This section asks the respondent to consider and rate her health today. Health was classified on five dimensions: mobility, self-care, usual activities, pain/discomfort and anxiety/depression. Health state values range from most severe impairment on all five dimensions (value $=-0.109$ ) to no problems on any dimension (value $=1.0$ ). We converted profiles of health status into a single summary index by applying scores from a valuation set from the UK (York). ${ }^{16} \mathrm{We}$ compared the first quartile (not in control of health status) of our study population with the other quartiles (in control of health status). The locus of control was measured by a single question about the extent of the perceived possibility of influencing lifestyle and/or health behaviour. Feelings towards pregnancy were measured by using the Pregnancy Related Anxiety Questionnaire (PRAQ). ${ }^{17}$ The scales used were 'fear of giving birth' (two items), 'fear of bearing a handicapped child' (four items) and 'concern about one's appearance' (three items). Items were scored on a four-point scale $(4=$ very true, $3=$ true, $2=$ not true, $1=$ certainly not 
Feijen-de Jong, E.I., Jansen, D.E.M.C., Baarveld, F., Boerleider, A.W., Spelten, E., Schellevis, F Reijneveld, S.A. Determinants of prenatal health care utilisation by low-risk women: a prospective cohort study. Women and Birth: 2015, 28(2), 87-94

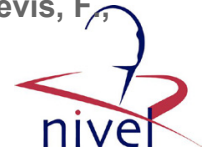

true). Every scale was dichotomised based on the distribution of the median score. In addition to the variable parity, we created a variable that included the difference between the number of pregnancies and the number of deliveries. We assumed that there could be a difference in prenatal health care utilisation between women with miscarriage(s) and/or abortion(s) in their medical history. Health behaviour variables consisted of questions related to substance use, folic acid use and body mass index (BMI). We removed drug abuse because none of the pregnant women reported drug use, which concurs with our sampling of low-risk pregnancies. Folic acid use was labelled as adequate when started at least four weeks before pregnancy. ${ }^{18}$ BMI was calculated using the weight and height before pregnancy registered by the respondent. We classified BMI according to the World Health Organisation classification of adult underweight, normal weight, overweight and obesity.

\section{[FIGURE 2]}

\subsection{Statistical analyses}

Firstly, we described background characteristics of the study population. Secondly, we assessed the determinants of inadequate health care utilisation by performing binary logistic regressions for the total group. We then split the research population into non-referred and referred pregnant women. Binary logistic regression was performed for both groups. Women receiving adequate health care utilisation were our reference group. The hierarchical structure of the data (respondents clustered in midwifery practices) revealed correlations within midwifery practices. Therefore, all analyses were undertaken in a multilevel framework. The variables in the final model are presented as odds ratios (OR) with $95 \%$ confidence intervals (CI). A two-tailed $p$-value of 0.05 or lower was considered statistically significant. Missing data accounted for less than $2.4 \%$ for all variables, with the exception of BMI $(6.8 \%)$. SPSS 21.0 (SPSS Inc., Chicago, IL) was used for all analyses.

\section{RESULTS}

Table 2 shows the characteristics of the study population, prenatal health care utilisation and referrals. The majority of the pregnant women were between 21 and 35 years of age $(84.5 \%)$, native Dutch $(84.8 \%)$, married $(96.5 \%)$, employed $(79.8 \%)$ and highly educated (48.8\%). Of all 3070 pregnant women, $24.7 \%$ made inadequate use of prenatal care, and $24.7 \%$ were referred to secondary care during pregnancy. A small percentage of women (4.7\%) made inadequate use of prenatal care and were also referred.

Table 3 shows the results of the analyses assessing the determinants of prenatal health care utilisation. Overall, it revealed that women of a non-Western origin (compared to native Dutch women), unemployed women, women reporting chronic illnesses or disabilities, and women who did not use folic acid periconceptionally had higher odds of using inadequate health care utilisation. No enabling variables showed a significant association with inadequate health care utilisation. 
Feijen-de Jong, E.I., Jansen, D.E.M.C., Baarveld, F., Boerleider, A.W., Spelten, E., Schellevis, F Reijneveld, S.A. Determinants of prenatal health care utilisation by low-risk women: a prospective cohort study. Women and Birth: 2015, 28(2), 87-94

\section{[TABLE 2]}

Split by referral status, among non-referred women, only predisposing and health behaviour variables showed a significant association with inadequate health care utilisation: women intending to deliver in the hospital under supervision of a midwife had higher odds of making inadequate use of prenatal care. Women who did not use folic acid periconceptionally (compared to adequate use), and women exposed to cigarette smoke during pregnancy (compared to non-exposed women) had higher odds of making inadequate use of prenatal care. Among referred women, need and health behaviour determinants showed significant results. Women reporting to have chronic illnesses or disabilities (compared to women not having chronic illnesses or disabilities) had higher odds of making inadequate use of prenatal care. This also counted for women who did not make adequate use of folic acid periconceptionally.

\section{DISCUSSION}

We assessed the determinants of inadequate prenatal health care utilisation of referred and non-referred women in primary midwifery practices in the Netherlands. Low-risk pregnant women (who were not referred during pregnancy) were found to be more likely to inadequately use prenatal care if they intended to deliver at hospital under the supervision of a midwife, if they did not use folic acid adequately periconceptionally, or if they were exposed to cigarette smoke during pregnancy. Among women who were referred to secondary care during pregnancy, those who reported chronic illnesses or disabilities, and those who did not use folic acid periconceptionally were more likely to make inadequate use of prenatal care than the remaining women.

A strength of this research is the use of a unique sample of women who were lowrisk at the start of their pregnancy. Next to this, we made a distinction between pregnant women who were referred and not-referred during pregnancy in order to delineate two groups; a consistently low-risk group, and a group needing specialised care during pregnancy. This allowed us to carry out the study in a homogeneous lowrisk population in primary midwifery care. In the Netherlands, $83 \%$ of women start pregnancy without any problems. ${ }^{19}$ Therefore, our study represents a large majority of all pregnant women. Finally, we used a database with many variables in a large study population. Therefore, we could include all of the dimensions of Anderson's model, enabling us to structure the large number of variables included in our database.

In the Netherlands, a low-risk pregnancy is defined on medical and obstetric criteria, although also other criteria (e.g. social factors as domestic violence, lack of facilities for existing children) are known to influence pregnancy risks. ${ }^{20}$ Currently, pilot studies are being undertaken to test the feasibility of including non-medical/obstetric criteria in the definition of low-risk pregnancy. Unfortunately, not all known determinants of inadequate prenatal care use could be included in our analyses due to absence of information about these factors. 
Feijen-de Jong, E.I., Jansen, D.E.M.C., Baarveld, F., Boerleider, A.W., Spelten, E., Schellevis, F Reijneveld, S.A. Determinants of prenatal health care utilisation by low-risk women: a prospective cohort study. Women and Birth: 2015, 28(2), 87-94

Regarding demographic characteristics, our study population included slightly more highly educated and native Dutch women compared to all pregnant women. ${ }^{19}$ This probably led to an underestimation of inadequate users. However, we found a similar percentage of women referred during pregnancy as is reported in national statistics. ${ }^{19}$ This supports the representativeness of our study. Finally, we did not measure the content of prenatal care, which is also an important indicator of adequacy of care. ${ }^{21}$

We found that $24.7 \%$ of the women who started care in primary midwifery care used prenatal care inadequately. This percentage would have been lower using for instance the prenatal schedule of the NICE guideline. ${ }^{15}$ Comparing our figures to a guideline from another country would be incorrect as professionals may generally be expected to meet their own professionals standard. It would, however, be very useful to compare guidelines on prenatal care between countries, including their evidence base.

The quite high percentage of underuse of prenatal care raises the question what the underlying mechanisms are for this inadequate use. Client-related and provider related factors may contribute to this underuse of prenatal care. With regard to clientrelated factors Dutch research is lacking. However, internationally Phillippi ${ }^{20}$ reported barriers which may also exist in the Netherlands, such as lack of familiarity with the maternal health care system (for primigravidae), language problems, and not knowing being pregnant. Provider-related factors may also contribute to underuse of prenatal care. After all, midwives inform pregnant women about prenatal care programme and invite them for follow-up consultations. Maybe, our finding reflects the way midwives adjust the number of visits to the preferences and wishes of pregnant women. Also, midwives themselves may experience barriers, which lead to less prenatal visits. However, to our knowledge evidence about provider-related factors in relation to adequacy of prenatal care use is not available.

We found similar determinants of inadequate prenatal health care utilisation as have been previously reported. ${ }^{6}$ However, regarding women who begin with primary midwifery care, who are all at low-risk, we found a limited set of determinants associated with inadequate health care utilisation. This is probably due to the group having consistently low-risk pregnancies. In a more heterogeneous population including both women with and without health risks during pregnancy - obstetric risk factors can confound or modify the role of determinants, which may lead to a larger set of determinants, which in fact denote subgroups of pregnant women with varying risks. Another explanation might be that because we used an adapted version of the Kotelchuck Index, the number of determinants and the strength of the associations found could have been affected. The factors that led to inadequate prenatal health care utilisation among non-referred low-risk pregnant women concerned predisposing variables and health behaviour variables. Regarding predisposing variables, the intended place of delivery showed a significant association with health care utilisation. Similar to Kupek et al., ${ }^{22}$ we found that women intending to deliver at a hospital under the supervision of a midwife were more likely to make inadequate use of prenatal care than women intending to deliver at home. This could be due by the characteristics of the population delivering in hospital. In a large study, de Jonge et al., ${ }^{23}$ found that Dutch women intending to 
Feijen-de Jong, E.I., Jansen, D.E.M.C., Baarveld, F., Boerleider, A.W., Spelten, E., Schellevis, F Reijneveld, S.A. Determinants of prenatal health care utilisation by low-risk women: a prospective cohort study. Women and Birth: 2015, 28(2), 87-94

deliver at a hospital were more likely to have a lower socio-economic position. The intended place of delivery may thus act as a proxy for socio-economic position. Regarding health behaviour variables, we found that folic acid utilisation (periconceptional behaviour) and passive smoking (prenatal behaviour) were determinants of inadequate health care utilisation. Both folic acid utilisation and passive smoking may act as proxy indicators for a less healthy lifestyle. ${ }^{24 \text { and } 25}$ Inadequate health care utilisation can also be an expression of a less healthy lifestyle or less health consciousness. ${ }^{24}$ However, we were not able to test this hypothesis, and thus it requires further research. Low-risk pregnant women whose pregnancy became high-risk (referred women) had a change of health status during pregnancy, leading to referral to secondary care. Determinants associated with inadequate prenatal health care utilisation among referred women included need and health behaviour determinants. Regarding need factors, women reporting chronic illnesses and disabilities were more likely to make inadequate use of prenatal care. It is probable that consulting other health practitioners may substitute for primary prenatal care in this case, including consulting general practitioners, ${ }^{26}$ obstetricians or other medical specialists. In addition, a significant health behaviour determinant was the failure to use folic acid periconceptionally, probably due to the same reason as that given by low-risk women. While we assessed individual characteristics associated with use of prenatal health care services, health care utilisation is also determined by characteristics of health services themselves, and by the interaction of the individual with the health care system and/or health care provider. We did not include these factors but acknowledge their importance, as also noted by Andersen et al. $^{12}$

Our findings have implications for both daily care and future research. We found that many pregnant women visit a midwife less frequently than they should as advised by professional guidelines, or entry care after the 12th week of gestation. Professional organisations have to be aware of this and should evaluate professional guidelines as to whether these are still adequate for Dutch primary midwifery care. The differences between guidelines on prenatal care further call for an international comparative study of these guidelines and their evidence base. Regarding care, our research can help midwives in low-risk settings to be alert on care patrons that possibly can lead to suboptimal outcomes which deviate from standard professional guidelines. Knowing about the determinants of inadequate HCU may give midwives an indication which women are vulnerable. In addition, a redesign of prenatal care could be considered - especially for women with less healthy lifestyles - which also takes client satisfaction with the services offered into account. For example, CenteringPregnancy is a model of group-based prenatal care that increases the odds of adequate health care utilisation ${ }^{27}$ in terms of number of visits. It includes physical assessment, education and peer support. ${ }^{27,28}$ and 29 Notwithstanding, in this model, early initiation of care is necessary and it also requires the training of maternal health care providers in other skills. ${ }^{30}$

\section{[TABLE 3]}

Future research is needed to gain an understanding of the reasons why women make inadequate use of prenatal primary care. What are the underlying reasons for certain 
Feijen-de Jong, E.I., Jansen, D.E.M.C., Baarveld, F., Boerleider, A.W., Spelten, E., Schellevis, F Reijneveld, S.A. Determinants of prenatal health care utilisation by low-risk women: a prospective cohort study. Women and Birth: 2015, 28(2), 87-94

groups? The content of care should also be included when measuring the adequacy of care. Our study can also provide a theoretical framework for future research integrating quantitative (content) and qualitative (reasons why) approaches to prenatal health care utilisation in primary care. Finally, next to assessing underuse of prenatal health care, assessment of overuse of prenatal care may be relevant as well. It may add information on the adequacy of prenatal guidelines, and on the costs associated with high use.

\section{CONCLUSION}

Our findings show that determinants of prenatal health care utilisation in primary care differ between women who are and women who are not referred to secondary care. Non-referred pregnant women were more likely to make inadequate use of prenatal care if they intended to deliver in hospital under the supervision of a midwife, if they did not use folic acid adequately periconceptionally, or if they were exposed to cigarette smoke during pregnancy. Women who were referred to secondary care were more likely to make inadequate use of prenatal care if reporting a chronic illnesses or disabilities, and if not using folic acid periconceptionally. Our results can be used to target interventions to women who are at risk of inadequate prenatal health care utilisation. At the same time, health care providers should be made aware of the groups we have identified because they are also at risk of making inadequate use of care. ${ }^{31}$

\section{ACKNOWLEDGEMENTS}

We would like to thank Myrte Westerneng and Monique Pereboom for their assistance in the data collection process for this study and Michiel de Boer for assistance with the data analyses.

\section{REFERENCES}

$1 \mathrm{E}$. Hemminki, M. Gissler Quantity and targetting of antenatal care in finland

2 K. Wildman, B. Blondel, J. Nijhuis, P. Defoort, C. Bakoula European indicators of health care during pregnancy, delivery and the postpartum period Eur J Obstet Gynecol Reprod Biol, 111 (Suppl. 1) (2003), pp. S53-S65

$3 \mathrm{~K}$. Raatikainen, N. Heiskanen, S. Heinonen Under-attending free antenatal care is associated with adverse pregnancy outcomes BMC Public Health, 7 (2007), p. 268

4 T.A. LaVeist, V.M. Keith, M.L. Gutierrez Black/white differences in prenatal care utilization: an assessment of predisposing and enabling factors Health Serv Res, 30 (1995), pp. 4358

5 T. Dowswell, G. Carroli, L. Duley, S. Gates, A.M. Gulmezoglu, D. Khan-Neelofur, et al.Alternative versus standard packages of antenatal care for low-risk pregnancy Cochrane Database Syst Rev (10) (2010), p. CD000934

6 E.I. Feijen-de Jong, D.E. Jansen, F. Baarveld, C.P. van der Schans, F.G. Schellevis, S.A. Reijneveld Determinants of late and/or inadequate use of prenatal healthcare in highincome countries: a systematic review Eur J Public Health, 22 (6) (2012), pp. 904-913

7 Birthplace in England Collaborative Group, P. Brocklehurst, P. Hardy, J. Hollowell, L. Linsell, A. Macfarlane, et al. Perinatal and maternal outcomes by planned place of birth for healthy women with low risk pregnancies: the birthplace in England national prospective cohort study BMJ, 343 (2011), p. d7400

8 Netherlands perinatal registry (PRN foundation). Perinatal care in the Netherlands (2011) 
Feijen-de Jong, E.I., Jansen, D.E.M.C., Baarveld, F., Boerleider, A.W., Spelten, E., Schellevis, F Reijneveld, S.A. Determinants of prenatal health care utilisation by low-risk women: a prospective cohort study. Women and Birth: 2015, 28(2), 87-94

9 L. Hingstman, R.J. Kenens Figures of GPs registration (cijfers uit de registratie van huisartsen; peiling 2011) NIVEL, Utrecht (2011)

10 M. De Geus Midwifery in the Netherlands Royal Dutch Organisation of Midwives, Utrecht (2012)

11 R. De Vries, M. Nieuwenhuijze, S.E. Buitendijk, Members of Midwifery Science Work Group What does it take to have a strong and independent profession of midwifery? Lessons from the Netherlands Midwifery, 29 (10) (2013), pp. 1122-1128

12 R.M. Andersen, T.H. Rice, G.F. Kominski Changing the U.S. health care system; key issues in health services policy and management Jossey-Bass, San Francisco, CA (2007)

13 J. Mannien, T. Klomp, T. Wiegers, M. Pereboom, J. Brug, A. de Jonge, et al.Evaluation of primary care midwifery in the Netherlands: Design and rationale of a dynamic cohort study (DELIVER) BMC Health Serv Res, 12 (1) (2012), p. 69

$14 \mathrm{M}$. Kotelchuck The adequacy of prenatal care utilization index: its US distribution and association with low birthweight Am J Public Health, 84 (9) (1994), pp. 1486-1489

15 National Institute for Health and, Clinical Excellence Routine care for the healthy pregnant woman Antenatal Care (2011)

16 M. Herdman, C. Gudex, A. Lloyd, M. Janssen, P. Kind, D. Parkin, et al. Development and preliminary testing of the new five-level version of EQ-5D (EQ-5D-5L) Qual Life Res, 20 (10) (2011), pp. 1727-1736

17 A.C. Huizink, E.J. Mulder, P.G. Robles de Medina, G.H. Visser, J.K. Buitelaar Is pregnancy anxiety a distinctive syndrome? Early Hum Dev, 79 (2) (2004), pp. 81-91

18 Health Council of the Netherlands Towards an optimal use of folic acid Health Council of the Netherlands, The Hague (2008) Report no.: 2008/02E

19 Netherlands Perinatal Registry Grote lijnen 10 jaar perinatale registratie Nederland Netherlands Perinatal Registry, Utrecht (2011)

20 J.C. Phillippi Women's perceptions of access to prenatal care in the united states: a literature review J Midwifery Womens Health, 54 (3) (2009), pp. 219-225

21 D.P. Misra, B. Guyer Benefits and limitations of prenatal care: from counting visits to measuring content JAMA, 279 (20) (1998), pp. 1661-1662

22 E. Kupek, S. Petrou, S. Vause, M. Maresh Clinical, provider and sociodemographic predictors of late initiation of antenatal care in England and Wales BJOG, 109 (3) (2002), pp. $265-273$

23 A. de Jonge, J.A. Mesman, J. Mannien, J.J. Zwart, J. van Dillen, J. van Roosmalen Severe adverse maternal outcomes among low risk women with planned home versus hospital births in the Netherlands: nationwide cohort study BMJ, 346 (2013), p. f3263

24 E.R. Ribeiro, A.M. Guimaraes, H. Bettiol, D.D. Lima, M.L. Almeida, L. de Souza, et al. Risk factors for inadequate prenatal care use in the metropolitan area of Aracaju, northeast Brazil BMC Pregnancy Childbirth, 9 (31) (2009), p. 2393

25 J. Mannien, A. de Jonge, M.C. Cornel, E. Spelten, E.K. Hutton Factors associated with not using folic acid supplements preconceptionally Public Health Nutr (2013), pp. 1-7

26 E.I. Feijen-de Jong, F. Baarveld, D.E. Jansen, J. Ursum, S.A. Reijneveld, F.G. Schellevis Do pregnant women contact their general practitioner? A register-based comparison of healthcare utilisation of pregnant and non-pregnant women in general practice BMC Fam Pract, 14 (2013), p. 10

27 J.R. Ickovics, T.S. Kershaw, C. Westdahl, U. Magriples, Z. Massey, H. Reynolds, et al. Group prenatal care and perinatal outcomes: a randomized controlled trial Obstet Gynecol, 110 (2 Pt 1) (2007), pp. 330-339

28 G. Rotundo Centering pregnancy Nurs Women's Health, 15 (6) (2011), pp. 508-518

29 T.E. Trudnak, E. Arboleda, R.S. Kirby, K. Perrin Outcomes of latina women in CenteringPregnancy group prenatal care compared with individual prenatal care $\mathrm{J}$ Midwifery Womens Health, 58 (4) (2013), pp. 396-403

30 G. Novick, A.E. Reid, J. Lewis, T.S. Kershaw, S.S. Rising, J.R. Ickovics Group prenatal care: model fidelity and outcomes Obstet Gynecol, 209 (2) (2013), p. 8:112.e1 112.e6

31 M.D. Kogan, G.R. Alexander, B.W. Jack, M.C. Allen The association between adequacy of prenatal care utilization and subsequent pediatric care utilization in the United States Pediatrics, 102 (1 Pt 1) (1998), pp. 25-30 
Feijen-de Jong, E.l., Jansen, D.E.M.C., Baarveld, F., Boerleider, A.W., Spelten, E., Schellevis, Reijneveld, S.A. Determinants of prenatal health care utilisation by low-risk women: a prospective cohort study. Women and Birth: 2015, 28(2), 87-94

\section{TABLES AND FIGURE}

Fig. 1. Eligible population, DELIVER cohort and research population. DELIVER, Data EersteLIjns VERloskunde (Dutch acronym for 'data primary care delivery').
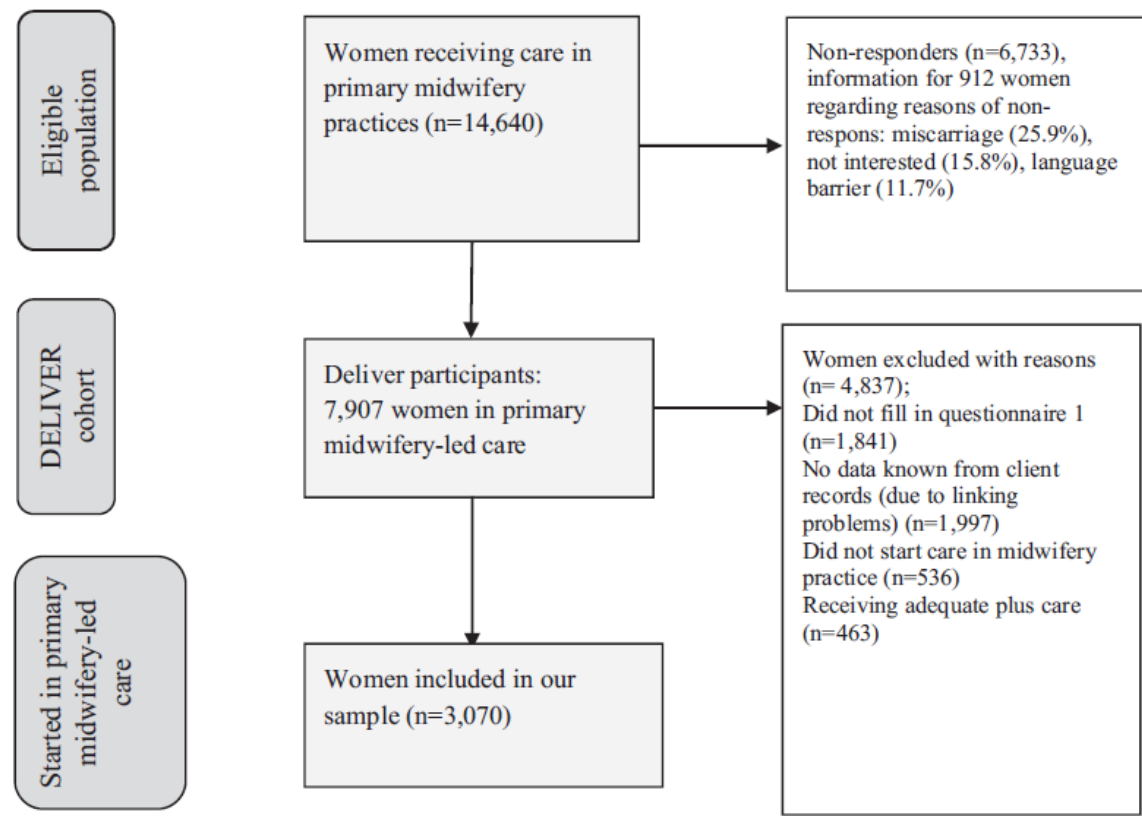

Table 1. Index for assessment of the adequacy of prenatal care utilisation in the Dutch primary midwifery care context (by A.W. Boerleider and E.I. Feijen-de Jong).

\begin{tabular}{|l|l||l|l||}
\hline $\begin{array}{c}\text { Duration of } \\
\text { gestation }\end{array}$ & $\begin{array}{c}\text { Initiation of } \\
\text { care }\end{array}$ & \multicolumn{1}{|c|}{$\begin{array}{c}\text { Number of } \\
\text { visits }\end{array}$} & $\begin{array}{c}\text { Kotelchuck } \\
\text { Index }\end{array}$ \\
\hline \hline $0-11+6$ & $\leq 11+6$ & 23 & 4 \\
\hline & & $1-2$ & 3 \\
\hline & & & 2 \\
\hline & & 0 & 1 \\
\hline $12-26+6$ & $\leq 11+6$ & $\geq 6$ & 4 \\
\hline Ideally 3.75 visits $^{\mathrm{a}}$ & & $3-5$ & 3 \\
\hline & & 2 & 2 \\
\hline & & $\leq 1$ & 1 \\
\hline \hline & $\geq 12+0$ & & 1 \\
\hline \hline $27-36+6$ & & 10 & 4 \\
\hline Ideally 7.5 visits $^{\mathrm{a}}$ & & $6-9$ & 3 \\
\hline \hline & & $4-5$ & 2 \\
\hline \hline & & $\leq 3$ & 1 \\
\hline \hline & $\geq 12+0$ & \\
\hline $37+0-37+6$ & $\leq 11+6$ & $\geq 13$ & 4 \\
\hline
\end{tabular}


Feijen-de Jong, E.I., Jansen, D.E.M.C., Baarveld, F., Boerleider, A.W., Spelten, E., Schellevis,

Reijneveld, S.A. Determinants of prenatal health care utilisation by low-risk women: a

prospective cohort study. Women and Birth: 2015, 28(2), 87-94

\begin{tabular}{|c|c|c|c|}
\hline $\begin{array}{l}\text { Duration of } \\
\text { gestation }\end{array}$ & $\begin{array}{c}\text { Initiation of } \\
\text { care }\end{array}$ & $\begin{array}{c}\text { Number of } \\
\text { visits }\end{array}$ & $\begin{array}{c}\text { Kotelchuck } \\
\text { Index }\end{array}$ \\
\hline \multirow[t]{4}{*}{ 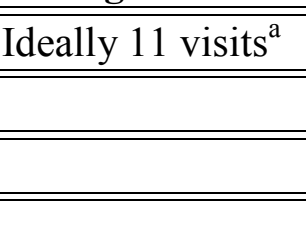 } & & $10-12$ & 3 \\
\hline & & $6-9$ & 2 \\
\hline & & $\leq 5$ & 1 \\
\hline & $\geq 12+0$ & 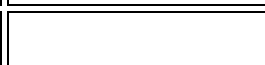 & 1 \\
\hline $38+0-38+6$ & $\leq 11+6$ & $\geq 14$ & 4 \\
\hline \multirow[t]{4}{*}{ Ideally 12 visits $^{\mathrm{a}}$} & & $10-13$ & 3 \\
\hline & & $6-9$ & 2 \\
\hline & & $\leq 5$ & 1 \\
\hline & $\geq 12+0$ & 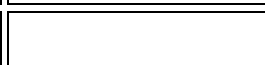 & 1 \\
\hline $39+0-39+6$ & $\leq 11+6$ & $\geq 15$ & 4 \\
\hline \multirow[t]{4}{*}{ Ideally 13 visits $^{\mathrm{a}}$} & & $11-14$ & 3 \\
\hline & & $7-10$ & 2 \\
\hline & & $\leq 6$ & 1 \\
\hline & $\geq 12+0$ & & 1 \\
\hline $40+0-40+6$ & $\leq 11+6$ & $\geq 16$ & 4 \\
\hline \multirow[t]{4}{*}{ 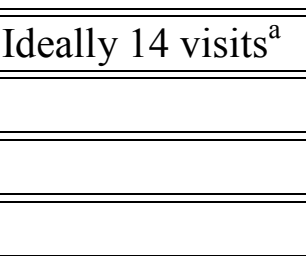 } & & $12-15$ & 3 \\
\hline & & $7-11$ & 2 \\
\hline & & $\leq 6$ & 1 \\
\hline & $\geq 12+0$ & & 1 \\
\hline $41+0-41+6$ & $\leq 11+6$ & $\geq 17$ & 4 \\
\hline \multirow[t]{4}{*}{ Ideally 15 visits $^{\mathrm{a}}$} & & $12-16^{*}$ & 3 \\
\hline & & $8-11$ & 2 \\
\hline & & $\leq 7$ & 1 \\
\hline & $\geq 12+0$ & & 1 \\
\hline
\end{tabular}

a) According to the guidelines of the Royal Dutch Organisation of Midwives.

b) Kotelchuck Index:

1. Inadequate (received less than $50 \%$ of expected visits).

2. Intermediate $(50-79 \%)$.

3. Adequate $(80-109 \%)$.

4. Adequate Plus (110\% and more). 
Feijen-de Jong, E.I., Jansen, D.E.M.C., Baarveld, F., Boerleider, A.W., Spelten, E., Schellevis, Reijneveld, S.A. Determinants of prenatal health care utilisation by low-risk women: a prospective cohort study. Women and Birth: 2015, 28(2), 87-94

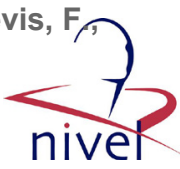

Fig. 2. Conceptual framework; Andersen's behavioural model, which shows the possible determinants of health care utilisation.

Predisposing variables

Demographic:

Age: $\leq 20 / 21-35 / \geq 36$

Social:

Ethnicity: Native Dutch/Western Non-Dutch/Non-Western

Marital status: married or living together/living alone

Occupation: employed/unemployed/disabled

Educational level: low (one to secondary education) middle

(to pre-university education) high (bachelor's degree to post-

graduate degree)

Beliefs:

Intended place of delivery: home/hospital birth centre with

own midwife/hospital con sultant-led

Religion: yes/no
Enabling variables

\section{Financing:}

Health insurance: basic/supplementary

Net household income: low income $(\leq$

€2000)/high income (> €2000)

\section{Organization:}

Accessibility of care:

* difficulties getting through when calling

during/outside business hours (yes/no)

* difficulties getting to and from the

midwifery practice (yes/no)
Need variables

Perceived health

General self-rated health: excellent-very good/good/fair-bad

Control of health situation(EQ-5d): no control of health situation/in

control of health situation

Locus of control: yes/no

Chronic illnesses, disabilities or disorders: yes/no

Feelings towards pregnancy (PRAQ-R):fear/no fear

Planned/wanted pregnancy: planned and wanted/unplanned but

wanted/unplanned and unwanted

Evaluated health

Parity'. nullipara/primipara, multipara

Gravidity/parity difference ${ }^{a}$ : difference $=1 /$ difference $>2$
Health behaviours

Folic acid use: adequate/inadequate/no

BMI: underweight/normal weight/

overweight/ obesity

Smoking: yes/no

Passive smoking: yes/no

Alcohol use: yes/no

\footnotetext{
${ }^{\mathrm{a}}$ Electronic client record
} 
Feijen-de Jong, E.I., Jansen, D.E.M.C., Baarveld, F., Boerleider, A.W., Spelten, E., Schellevis, F Reijneveld, S.A. Determinants of prenatal health care utilisation by low-risk women: a prospective cohort study. Women and Birth: 2015, 28(2), 87-94

Table 2. Healthcare utilisation and referrals in primary midwifery care (descriptives, $N=3070)$.

\begin{tabular}{|c|c|c|c|c|c|}
\hline \multicolumn{6}{|c|}{ Healthcare utilisation $n(\%)$} \\
\hline Adequate & \multicolumn{5}{|r|}{$2312(75.3)$} \\
\hline Inadequate & \multicolumn{5}{|r|}{$758(24.7)$} \\
\hline \multicolumn{6}{|l|}{ Referrals $n(\%)$} \\
\hline Non-referred & \multicolumn{5}{|r|}{$2313(75.3)$} \\
\hline Referred & \multicolumn{5}{|r|}{$757(24.7)$} \\
\hline \multirow[t]{2}{*}{$\begin{array}{c}\text { Background } \\
\text { characteristic } \\
\text { s } \\
\end{array}$} & $n(\%)$ & $\begin{array}{l}\text { Adequate/n } \\
\text { on-referred }\end{array}$ & Adequate/referred & $\begin{array}{c}\text { Inadequate/non- } \\
\text { referred }\end{array}$ & Inadequate/referred \\
\hline & & $1699(55.3)$ & $613(20.0)$ & $614(20.0)$ & $144(4.7)$ \\
\hline \multicolumn{6}{|l|}{ Age $(n=3065)$} \\
\hline$\leq 20$ & $40(1.3)$ & $22(0.7)$ & $4(0.1)$ & $10(0.3)$ & $4(0.1)$ \\
\hline $21-35^{\mathrm{a}}$ & \begin{tabular}{|l}
2595 \\
$(84.5)$ \\
\end{tabular} & $1472(48.0)$ & $500(16.3)$ & 509 (16.6) & $114(3.7)$ \\
\hline$\geq 36$ & \begin{tabular}{|l}
430 \\
$(14.0)$
\end{tabular} & $204(6.7)$ & $107(3.5)$ & $93(3.0)$ & $26(0.8)$ \\
\hline \multicolumn{6}{|c|}{ Ethnicity $(n=3065)$} \\
\hline Native Dutch ${ }^{\mathrm{a}}$ & $\begin{array}{l}2599 \\
(84.8)\end{array}$ & $1443(47.1)$ & $533(17.4)$ & $507(16.5)$ & || $116(3.8)$ \\
\hline Non-Western & $252(8.2)$ & $128(4.2)$ & $36(1.2)$ & $68(2.2)$ & $20(0.7)$ \\
\hline $\begin{array}{l}\text { Western Non- } \\
\text { Dutch }\end{array}$ & $214(7.0)$ & $125(4.1)$ & $43(1.4)$ & $39(1.3)$ & $7(0.2)$ \\
\hline \multicolumn{6}{|c|}{ Marital status $(n=3067)$} \\
\hline $\begin{array}{l}\text { Married or } \\
\text { living } \\
\text { together }^{\mathrm{a}}\end{array}$ & $\begin{array}{l}2959 \\
(96.5)\end{array}$ & $1647(53.7)$ & $588(19.2)$ & $590(19.2)$ & $134(4.4)$ \\
\hline Living alone & $108(3.5)$ & $50(1.6)$ & $25(0.8)$ & $23(0.7)$ & $10(0.3)$ \\
\hline \multicolumn{6}{|c|}{ Occupation $(n=3064)$} \\
\hline Employed $^{\mathrm{a}}$ & $\begin{array}{l}2446 \\
(79.8)\end{array}$ & $1374(44.8)$ & $497(16.2)$ & $468(15.3)$ & $107(3.5)$ \\
\hline Unemployed & \begin{tabular}{|l}
572 \\
$(18.7)$ \\
\end{tabular} & $304(9.9)$ & $100(3.3)$ & $132(4.3)$ & $36(1.2)$ \\
\hline Disabled & $46(1.5)$ & $19(0.6)$ & $13(0.4)$ & $13(0.4)$ & $1(0.0)$ \\
\hline \multicolumn{6}{|c|}{ Educational level $(n=3063)$} \\
\hline Low $^{\mathrm{a}}$ & \begin{tabular}{|l|}
472 \\
$(15.4)$ \\
\end{tabular} & $237(7.7)$ & $98(3.2)$ & $105(3.4)$ & $32(1.0)$ \\
\hline Middle & 1095 & $603(19.7)$ & $238(7.8)$ & $208(6.8)$ & $46(1.5)$ \\
\hline
\end{tabular}


Feijen-de Jong, E.I., Jansen, D.E.M.C., Baarveld, F., Boerleider, A.W., Spelten, E., Schellevis, F/ Reijneveld, S.A. Determinants of prenatal health care utilisation by low-risk women: a prospective cohort study. Women and Birth: 2015, 28(2), 87-94

\begin{tabular}{|c|c|c|c|c|c|}
\hline $\begin{array}{c}\text { Background } \\
\text { characteristic } \\
\text { s } \\
\end{array}$ & $n(\%)$ & $\begin{array}{l}\text { Adequate/n } \\
\text { on-referred }\end{array}$ & Adequate/referred & $\begin{array}{c}\text { Inadequate/non- } \\
\text { referred }\end{array}$ & Inadequate/referred \\
\hline & & $1699(55.3)$ & $613(20.0)$ & $614(20.0)$ & $144(4.7)$ \\
\hline & $(35.7)$ & & & & \\
\hline High & $\begin{array}{l}\begin{array}{l}1496 \\
(48.8)\end{array} \\
\end{array}$ & $856(27.9)$ & $274(8.9)$ & $300(9.8)$ & $66(2.2)$ \\
\hline \multicolumn{6}{|c|}{ Parity $(n=3062)$} \\
\hline Nullipara $^{\mathrm{a}}$ & $\begin{array}{l}1227 \\
(40.1)\end{array}$ & $706(23.1)$ & $237(7.7)$ & $222(7.3)$ & $62(2.0)$ \\
\hline $\begin{array}{l}\text { Primi/multipa } \\
\text { ra }\end{array}$ & $\begin{array}{l}1835 \\
(59.9)\end{array}$ & 987 (32.2) & $374(12.2)$ & $392(12.8)$ & $82(2.7)$ \\
\hline
\end{tabular}

a) Reference categories.

Table 3. Associations of various characteristics with inadequate prenatal health care utilisation for all women who initiated prenatal visits at primary care level, and split by subsequent referral (no and yes): odds ratios (OR) and 95\% confidence intervals (CI).

\begin{tabular}{|c|c|c|c|c|c|c|}
\hline & \multicolumn{2}{|c|}{$\begin{array}{c}\text { Overall } \\
N=\mathbf{3 0 7 0}\end{array}$} & \multicolumn{2}{|c|}{$\begin{array}{c}\text { Not referred } \\
n=1425\end{array}$} & \multicolumn{2}{|c|}{$\begin{array}{l}\text { Referred } \\
n=1645\end{array}$} \\
\hline & $\begin{array}{l}\text { Crude OR } \\
\text { (CI) }\end{array}$ & $\begin{array}{l}\text { Adjusted OR } \\
(\mathrm{CI})^{\mathrm{a}}\end{array}$ & $\begin{array}{c}\text { Crude } \\
\text { OR } \\
\text { (CI) }\end{array}$ & $\begin{array}{l}\text { Adjusted } \\
\text { OR (CI) }\end{array}$ & $\begin{array}{c}\text { Crude } \\
\text { OR } \\
\text { (CI) }\end{array}$ & $\begin{array}{l}\text { Adjusted } \\
\text { OR (CI) }\end{array}$ \\
\hline \multicolumn{7}{|c|}{ Predisposing variables } \\
\hline \multicolumn{7}{|l|}{ Age (years) } \\
\hline$\leq 20$ & $\begin{array}{l}2.48(1.22- \\
5.06)\end{array}$ & & \begin{tabular}{|l}
1.97 \\
$(0.86-$ \\
$4.51)$ \\
\end{tabular} & & \begin{tabular}{|l|}
6.89 \\
$(1.56-$ \\
$30.16)$ \\
\end{tabular} & \\
\hline$\geq 36$ & $\begin{array}{l}1.27(0.98- \\
1.64)\end{array}$ & & $\begin{array}{l}1.50 \\
(1.10- \\
2.03) \\
\end{array}$ & & \begin{tabular}{|l}
1.03 \\
$(0.63-$ \\
$1.68)$ \\
\end{tabular} & \\
\hline Ref. $21-35$ & 1.00 (ref.) & & $\begin{array}{l}1.00 \\
\text { (ref.) }\end{array}$ & & \begin{tabular}{|l|}
1.00 \\
(ref.)
\end{tabular} & \\
\hline \multicolumn{7}{|l|}{ Ethnicity } \\
\hline Non-western & $\begin{array}{l}2.05(1.48- \\
2.85)\end{array}$ & $\begin{array}{l}1.56(1.11- \\
2.21)\end{array}$ & $\begin{array}{l}1.83 \\
(1.25- \\
2.68) \\
\end{array}$ & & \begin{tabular}{|l|}
2.43 \\
$(1.28-$ \\
$4.60)$ \\
\end{tabular} & \\
\hline $\begin{array}{l}\text { Western non- } \\
\text { Dutch }\end{array}$ & $\begin{array}{l}0.93(0.64- \\
1.35)\end{array}$ & $\begin{array}{l}0.88(0.61- \\
1.28)\end{array}$ & $\begin{array}{l}0.95 \\
(0.62- \\
1.46)\end{array}$ & & $\begin{array}{l}0.76 \\
(0.33- \\
1.76)\end{array}$ & \\
\hline
\end{tabular}


Feijen-de Jong, E.I., Jansen, D.E.M.C., Baarveld, F., Boerleider, A.W., Spelten, E., Schellevis, F Reijneveld, S.A. Determinants of prenatal health care utilisation by low-risk women: a prospective cohort study. Women and Birth: 2015, 28(2), 87-94

\begin{tabular}{|c|c|c|c|c|c|c|}
\hline & \multicolumn{2}{|c|}{$\begin{array}{c}\text { Overall } \\
N=\mathbf{3 0 7 0}\end{array}$} & \multicolumn{2}{|c|}{$\begin{array}{c}\text { Not referred } \\
n=1425\end{array}$} & \multicolumn{2}{|c|}{$\begin{array}{l}\text { Referred } \\
n=1645\end{array}$} \\
\hline & $\begin{array}{l}\text { Crude OR } \\
\text { (CI) }\end{array}$ & $\begin{array}{l}\text { Adjusted OR } \\
(\mathrm{CI})^{\mathrm{a}}\end{array}$ & \begin{tabular}{||c|} 
Crude \\
OR \\
(CI) \\
\end{tabular} & $\begin{array}{l}\text { Adjusted } \\
\text { OR (CI) }\end{array}$ & \begin{tabular}{|c|} 
Crude \\
OR \\
(CI) \\
\end{tabular} & $\begin{array}{l}\text { Adjusted } \\
\text { OR (CI) }\end{array}$ \\
\hline Native Dutch & 1.00 (ref.) & 1.00 (ref.) & $\begin{array}{l}1.00 \\
\text { (ref.) }\end{array}$ & & $\begin{array}{l}1.00 \\
\text { (ref.) }\end{array}$ & \\
\hline \multicolumn{7}{|l|}{ Marital status } \\
\hline Living alone & $\begin{array}{l}1.77(1.13- \\
2.78)\end{array}$ & & $\begin{array}{l}1.89 \\
(1.09- \\
3.28)\end{array}$ & & \begin{tabular}{|l}
.77 \\
$(0.81-$ \\
$3.91)$ \\
\end{tabular} & \\
\hline $\begin{array}{l}\text { Married or living } \\
\text { together }\end{array}$ & 1.00 (ref.) & & $\begin{array}{l}1.00 \\
\text { (ref.) }\end{array}$ & & $\begin{array}{l}1.00 \\
\text { (ref.) }\end{array}$ & \\
\hline \multicolumn{7}{|l|}{ Occupation } \\
\hline Unemployed & $\begin{array}{l}1.67(1.33- \\
2.10)\end{array}$ & $\begin{array}{l}1.36(1.06- \\
1.73)\end{array}$ & \begin{tabular}{|l|}
1.56 \\
$(1.19-$ \\
$2.03)$
\end{tabular} & & \begin{tabular}{|l}
1.96 \\
$(1.24-$ \\
$3.11)$
\end{tabular} & \\
\hline Disabled & $\begin{array}{l}1.00(0.49- \\
2.04)\end{array}$ & $\begin{array}{l}0.77(0.37- \\
1.59)\end{array}$ & \begin{tabular}{|l}
1.27 \\
$(0.55-$ \\
$2.92)$ \\
\end{tabular} & & \begin{tabular}{|l}
.40 \\
$(0.05-$ \\
$3.25)$ \\
\end{tabular} & \\
\hline Ref. Employed & 1.00 (ref.) & 1.00 (ref.) & $\begin{array}{l}1.00 \\
\text { (ref.) }\end{array}$ & & $\begin{array}{l}1.00 \\
\text { (ref.) }\end{array}$ & \\
\hline \multicolumn{7}{|l|}{ Educational level } \\
\hline Middle & $\begin{array}{l}0.68(0.52- \\
0.88)\end{array}$ & & \begin{tabular}{|l|}
0.74 \\
$(0.54-$ \\
$1.02)$ \\
\end{tabular} & & \begin{tabular}{|l|}
0.55 \\
$(0.33-$ \\
$0.94)$ \\
\end{tabular} & \\
\hline High & $\begin{array}{l}0.67(0.52- \\
0.87)\end{array}$ & & \begin{tabular}{|l}
0.69 \\
$(0.51-$ \\
$0.94)$ \\
\end{tabular} & & \begin{tabular}{|l}
0.64 \\
$(0.39-$ \\
$1.07)$ \\
\end{tabular} & \\
\hline Low & 1.00 (ref.) & & $\begin{array}{l}1.00 \\
\text { (ref.) }\end{array}$ & & $\begin{array}{l}1.00 \\
\text { (ref.) }\end{array}$ & \\
\hline \multicolumn{7}{|c|}{ Intended place of delivery } \\
\hline $\begin{array}{l}\text { Hospital/birth } \\
\text { centre midwifery- } \\
\text { led }\end{array}$ & $\begin{array}{l}1.29(1.06- \\
1.56)\end{array}$ & & \begin{tabular}{|l|}
1.45 \\
$(1.16-$ \\
$1.81)$ \\
\end{tabular} & \begin{tabular}{|l}
$1.43(1.14$ \\
$1.79)$
\end{tabular} & \begin{tabular}{|l}
.87 \\
$(0.59-$ \\
$1.28)$
\end{tabular} & \\
\hline $\begin{array}{l}\text { Hospital } \\
\text { consultant-led }\end{array}$ & $\begin{array}{l}2.14(1.19- \\
3.85)\end{array}$ & & \begin{tabular}{|l}
2.05 \\
$(0.97-$ \\
$4.30)$ \\
\end{tabular} & $\begin{array}{l}1.71(0.81- \\
3.60)\end{array}$ & \begin{tabular}{|l|}
.63 \\
$(1.01-$ \\
$6.88)$ \\
\end{tabular} & \\
\hline Home & 1.00 (ref.) & & $\mid \begin{array}{l}1.00 \\
\text { (ref.) }\end{array}$ & 1.00 (ref.) & $\begin{array}{l}1.00 \\
\text { (ref.) }\end{array}$ & \\
\hline
\end{tabular}


Feijen-de Jong, E.I., Jansen, D.E.M.C., Baarveld, F., Boerleider, A.W., Spelten, E., Schellevis, F/ Reijneveld, S.A. Determinants of prenatal health care utilisation by low-risk women: a prospective cohort study. Women and Birth: 2015, 28(2), 87-94

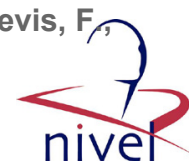

\begin{tabular}{|c|c|c|c|c|c|c|}
\hline & \multicolumn{2}{|c|}{$\begin{array}{c}\text { Overall } \\
N=\mathbf{3 0 7 0}\end{array}$} & \multicolumn{2}{|c|}{$\begin{array}{c}\text { Not referred } \\
n=1425\end{array}$} & \multicolumn{2}{|c|}{$\begin{array}{l}\text { Referred } \\
n=1645\end{array}$} \\
\hline & $\begin{array}{l}\text { Crude OR } \\
\text { (CI) }\end{array}$ & $\begin{array}{l}\text { Adjusted OR } \\
\qquad(\mathrm{CI})^{\mathrm{a}}\end{array}$ & \begin{tabular}{|c} 
Crude \\
OR \\
(CI) \\
\end{tabular} & $\begin{array}{l}\text { Adjusted } \\
\text { OR (CI })^{\mathrm{a}}\end{array}$ & \begin{tabular}{|c} 
Crude \\
OR \\
(CI) \\
\end{tabular} & $\begin{array}{l}\text { Adjusted } \\
\text { OR (CI) }\end{array}$ \\
\hline No & $\begin{array}{l}0.96(0.78- \\
1.17)\end{array}$ & & $\begin{array}{l}0.97 \\
(0.77- \\
1.23) \\
\end{array}$ & & $\begin{array}{l}0.91 \\
(0.60- \\
1.36) \\
\end{array}$ & \\
\hline Yes & 1.00 (ref.) & & $\begin{array}{l}1.00 \\
\text { (ref.) }\end{array}$ & & $\begin{array}{l}1.00 \\
\text { (ref.) }\end{array}$ & \\
\hline
\end{tabular}

Enabling variables

Basic and supplementary health care insurance

\begin{tabular}{|c|c|c|c|}
\hline $\begin{array}{l}\text { Basic and } \\
\text { supplementary }\end{array}$ & $\begin{array}{l}0.87(0.67- \\
1.21)\end{array}$ & $\begin{array}{l}0.87 \\
(0.64 \\
1.17) \\
\end{array}$ & $\begin{array}{l}0.88 \\
(0.53- \\
1.48) \\
\end{array}$ \\
\hline Basic & 1.00 (ref.) & $\mid \begin{array}{l}1.00 \\
\text { (ref.) }\end{array}$ & \begin{tabular}{|l}
1.00 \\
(ref.)
\end{tabular} \\
\hline
\end{tabular}

Net household income

\begin{tabular}{|c|c|c|c|}
\hline$>€ 2000$ & $\begin{array}{l}0.63(0.49 \\
0.81)\end{array}$ & $\begin{array}{l}0.62 \\
(0.46- \\
0.83)\end{array}$ & $\begin{array}{l}0.64 \\
(0.39 \\
1.06)\end{array}$ \\
\hline$<€ 2000$ & 1.00 (ref.) & $\left(\begin{array}{l}1.00 \\
\text { (ref.) }\end{array}\right.$ & $\left(\begin{array}{l}1.00 \\
\text { (ref.) }\end{array}\right.$ \\
\hline
\end{tabular}

Accessibility of care (phone)

\begin{tabular}{|c|c|c|c|}
\hline Problems & $\begin{array}{l}1.08(0.85- \\
1.37)\end{array}$ & \begin{tabular}{|l|}
1.10 \\
$(0.83-$ \\
$1.44)$
\end{tabular} & \begin{tabular}{|l}
1.06 \\
$(0.65-$ \\
$1.73)$
\end{tabular} \\
\hline No problems & 1.00 (ref.) & $\begin{array}{l}1.00 \\
\text { (ref.) }\end{array}$ & $\begin{array}{l}1.00 \\
\text { (ref.) }\end{array}$ \\
\hline
\end{tabular}

Accessibility of care (getting to and from the practice)

\begin{tabular}{|c|c|c|c|}
\hline Problems & $\begin{array}{l}1.26(0.79- \\
1.99)\end{array}$ & $\mid \begin{array}{l}1.18 \\
(0.69- \\
2.02)\end{array}$ & $\mid \begin{array}{l}1.11 \\
0.43- \\
2.88)\end{array}$ \\
\hline No problems & 1.00 (ref.) & \begin{tabular}{|l|l}
1.00 \\
(ref.)
\end{tabular} & $\begin{array}{l}1.00 \\
\text { (ref.) }\end{array}$ \\
\hline \multicolumn{4}{|l|}{ Need variables } \\
\hline \multicolumn{4}{|c|}{ General self-rated health } \\
\hline $\begin{array}{l}\text { Excellent/Very } \\
\text { good }\end{array}$ & $\begin{array}{l}0.92(0.75- \\
1.11)\end{array}$ & \begin{tabular}{|l|}
0.92 \\
$(0.74-$ \\
$1.15)$
\end{tabular} & $\begin{array}{l}0.89 \\
(0.69- \\
1.35)\end{array}$ \\
\hline
\end{tabular}


Feijen-de Jong, E.I., Jansen, D.E.M.C., Baarveld, F., Boerleider, A.W., Spelten, E., Schellevis, F Reijneveld, S.A. Determinants of prenatal health care utilisation by low-risk women: a prospective cohort study. Women and Birth: 2015, 28(2), 87-94

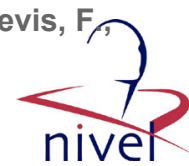

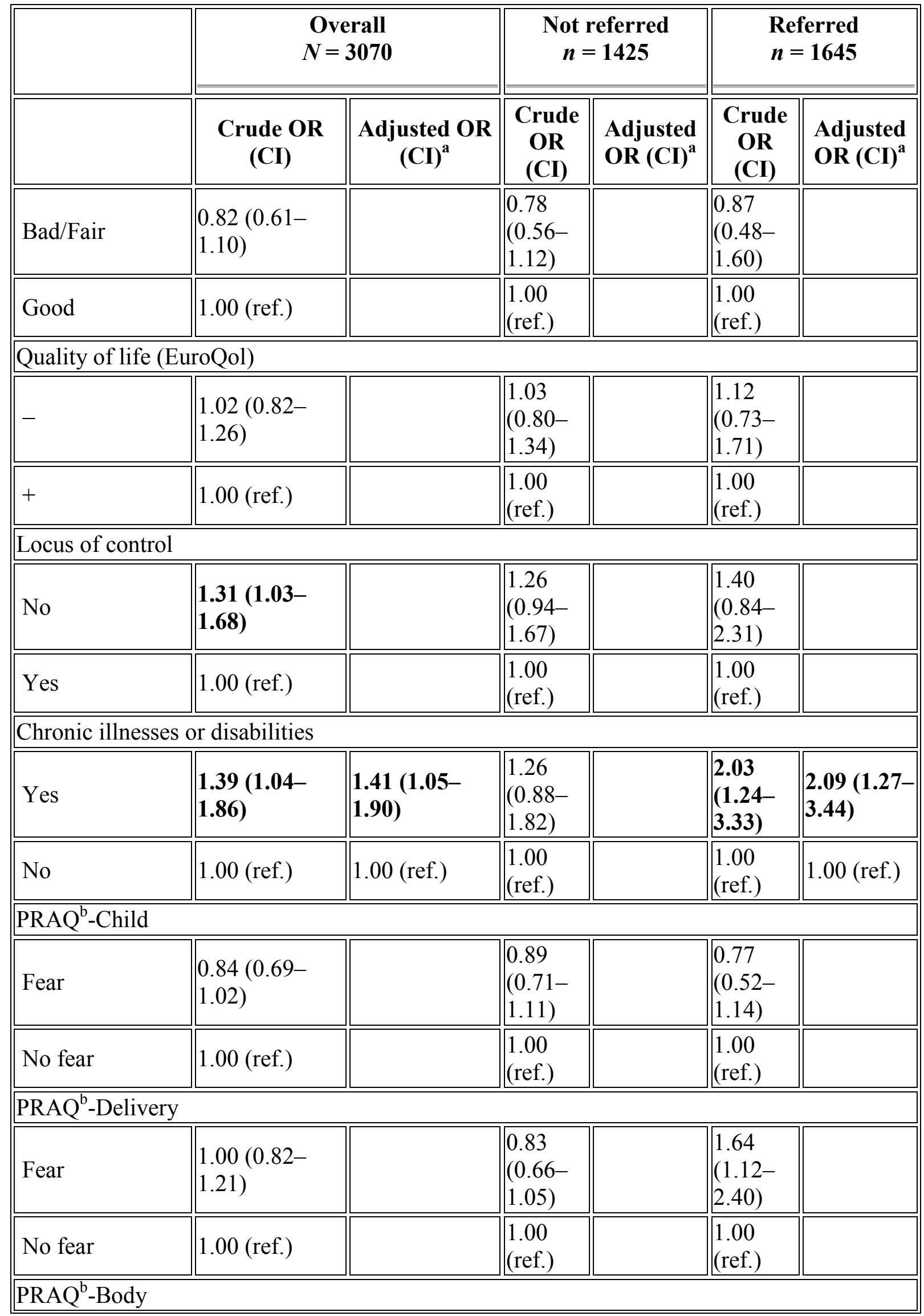


Feijen-de Jong, E.I., Jansen, D.E.M.C., Baarveld, F., Boerleider, A.W., Spelten, E., Schellevis, F/ Reijneveld, S.A. Determinants of prenatal health care utilisation by low-risk women: a prospective cohort study. Women and Birth: 2015, 28(2), 87-94

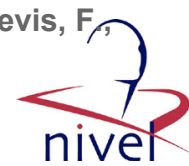

\begin{tabular}{|c|c|c|c|c|c|c|}
\hline & \multicolumn{2}{|c|}{$\begin{array}{c}\text { Overall } \\
N=\mathbf{3 0 7 0}\end{array}$} & \multicolumn{2}{|c|}{$\begin{array}{l}\text { Not referred } \\
n=1425\end{array}$} & \multicolumn{2}{|c|}{$\begin{array}{c}\text { Referred } \\
n=1645\end{array}$} \\
\hline & $\begin{array}{l}\text { Crude OR } \\
\text { (CI) }\end{array}$ & $\begin{array}{l}\text { Adjusted OR } \\
\text { (CI) }\end{array}$ & $\begin{array}{c}\text { Crude } \\
\text { OR } \\
\text { (CI) }\end{array}$ & $\begin{array}{l}\text { Adjusted } \\
\text { OR (CI) }\end{array}$ & \begin{tabular}{|c|} 
Crude \\
OR \\
(CI) \\
\end{tabular} & $\begin{array}{l}\text { Adjusted } \\
\text { OR (CI) }\end{array}$ \\
\hline Fear & $\begin{array}{l}0.93(0.76- \\
1.13)\end{array}$ & & $\begin{array}{l}0.94 \\
(0.74- \\
1.18) \\
\end{array}$ & & $\begin{array}{l}1.02 \\
(0.69- \\
1.51)\end{array}$ & \\
\hline No fear & 1.00 (ref.) & & $\begin{array}{l}1.00 \\
\text { (ref.) }\end{array}$ & & $\begin{array}{l}1.00 \\
\text { (ref.) }\end{array}$ & \\
\hline \multicolumn{7}{|c|}{ Planned and wantedness of pregnancy ${ }^{\mathrm{c}}$} \\
\hline $\begin{array}{l}\text { Wanted, not } \\
\text { planned }\end{array}$ & $\begin{array}{l}1.42(1.13- \\
1.79)\end{array}$ & & \begin{tabular}{|l|}
1.34 \\
$(1.02-$ \\
$1.76)$ \\
\end{tabular} & & \begin{tabular}{|l|}
1.64 \\
$(1.05-$ \\
$2.58)$ \\
\end{tabular} & \\
\hline $\begin{array}{l}\text { Planned and } \\
\text { wanted }\end{array}$ & 1.00 (ref.) & & $\begin{array}{l}1.00 \\
\text { (ref.) }\end{array}$ & & $\begin{array}{l}1.00 \\
\text { (ref.) }\end{array}$ & \\
\hline \multicolumn{7}{|l|}{ Parity } \\
\hline Primi/multipara & $\begin{array}{l}1.22(1.02- \\
1.47)\end{array}$ & & \begin{tabular}{|l}
1.36 \\
$(1.10-$ \\
$1.69)$ \\
\end{tabular} & & \begin{tabular}{|l}
0.84 \\
$(0.58-$ \\
$1.23)$ \\
\end{tabular} & \\
\hline Nullipara & 1.00 (ref.) & & $\begin{array}{l}1.00 \\
\text { (ref.) }\end{array}$ & & $\begin{array}{l}1.00 \\
\text { (ref.) }\end{array}$ & \\
\hline \multicolumn{7}{|c|}{ Difference between number of pregnancies and number of births } \\
\hline$\geq 2$ & $\begin{array}{l}1.17(0.95- \\
1.44)\end{array}$ & & $\begin{array}{l}1.17 \\
(0.92- \\
1.49)\end{array}$ & & \begin{tabular}{|l}
1.22 \\
$(0.81-$ \\
$1.85)$ \\
\end{tabular} & \\
\hline 1 & 1.00 (ref.) & & $\begin{array}{l}1.00 \\
\text { (ref.) }\end{array}$ & & $\begin{array}{l}1.00 \\
\text { (ref.) }\end{array}$ & \\
\hline \multicolumn{7}{|c|}{ Health behaviour variables } \\
\hline \multicolumn{7}{|c|}{ Folic acid utilisation } \\
\hline No & $\begin{array}{l}2.42(1.78- \\
3.29)\end{array}$ & $\begin{array}{l}1.93(1.40- \\
2.68)\end{array}$ & \begin{tabular}{|l|}
2.20 \\
$(1.53-$ \\
$3.16)$ \\
\end{tabular} & $\begin{array}{l}1.89(1.30- \\
2.75)\end{array}$ & \begin{tabular}{|l|}
3.06 \\
$(1.70-$ \\
$5.50)$ \\
\end{tabular} & \begin{tabular}{|l}
$3.14(1.74$ \\
$5.67)$
\end{tabular} \\
\hline $\begin{array}{l}\text { Yes, } \\
\text { inadequately }\end{array}$ & $\begin{array}{l}1.26(1.03- \\
1.53)\end{array}$ & $\begin{array}{l}1.20(0.99- \\
1.47)\end{array}$ & \begin{tabular}{|l}
1.20 \\
$(0.95-$ \\
$1.50)$ \\
\end{tabular} & $\begin{array}{l}1.18(0.94- \\
1.48)\end{array}$ & \begin{tabular}{|l}
1.38 \\
$(0.90-$ \\
$2.09)$ \\
\end{tabular} & $\begin{array}{l}1.34(0.88 \\
2.05)\end{array}$ \\
\hline Yes, adequately & 1.00 (ref.) & 1.00 (ref.) & $\begin{array}{l}1.00 \\
\text { (ref.) }\end{array}$ & 1.00 (ref.) & $\begin{array}{l}1.00 \\
\text { (ref.) }\end{array}$ & 1.00 (ref.) \\
\hline \multicolumn{7}{|l|}{ BMI } \\
\hline$\leq 18.5$ & \begin{tabular}{|l}
$1.02(0.60-$ \\
$1.76)$ \\
\end{tabular} & & $\begin{array}{l}1.31 \\
0.72- \\
\end{array}$ & & \begin{tabular}{|l|}
0.42 \\
$(0.09-$ \\
\end{tabular} & \\
\hline
\end{tabular}


Feijen-de Jong, E.I., Jansen, D.E.M.C., Baarveld, F., Boerleider, A.W., Spelten, E., Schellevis, F/

Reijneveld, S.A. Determinants of prenatal health care utilisation by low-risk women: a

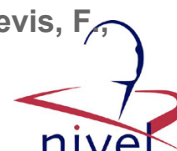

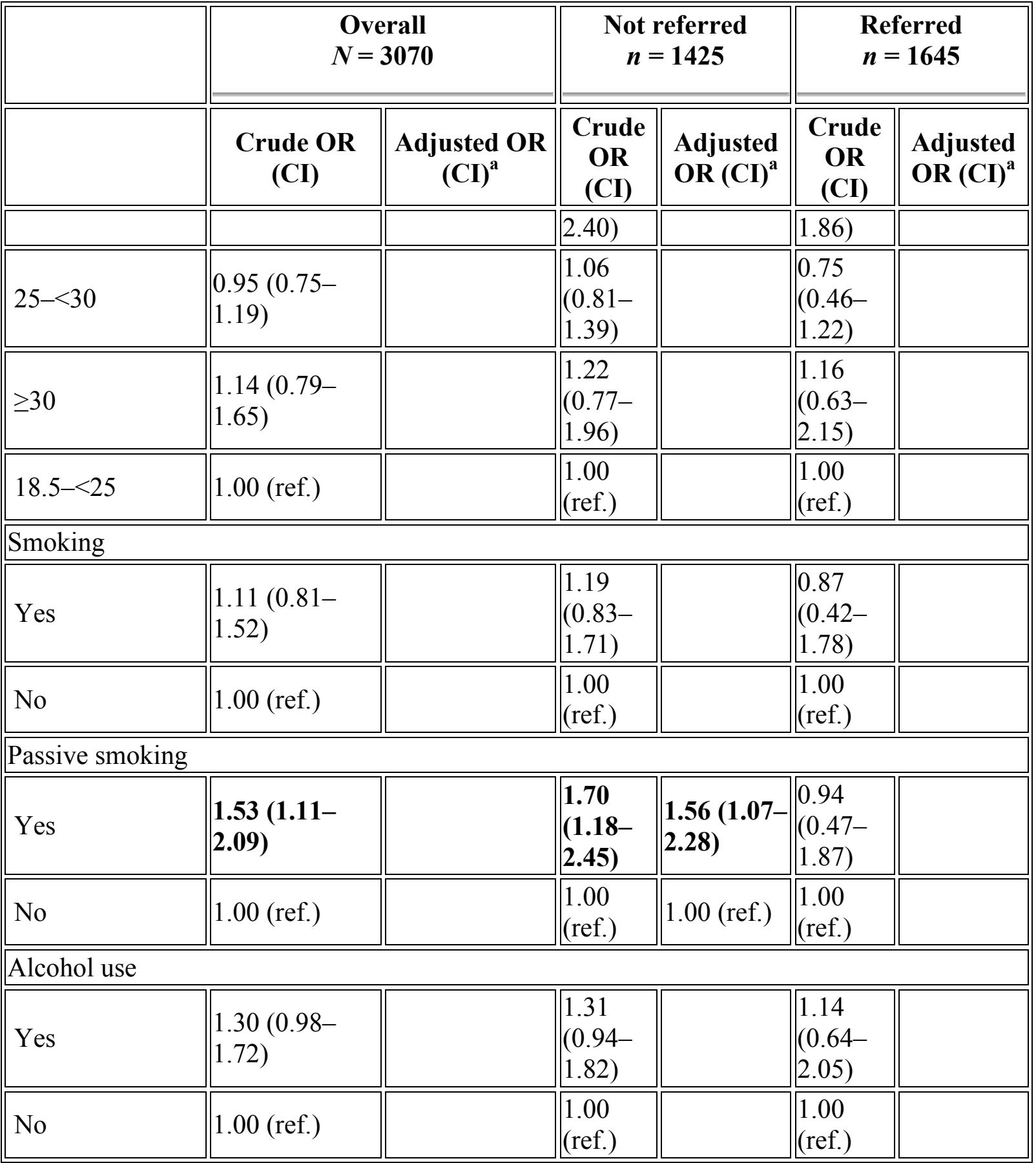

a) Statistically significant results are presented in bold print.

b) Corrected for all other variables.

c) PRAQ = Pregnancy Related Anxiety Questionnaire.

d) Category 'not wanted, not planned' removed due to empty cells 